\title{
Erratum to: Neither property right nor heroic gift, neither sacrifice nor aporia: the benefit of the theoretical lens of sharing in donation ethics
}

\author{
Kristin Zeiler
}

Published online: 25 December 2013

(C) Springer Science+Business Media Dordrecht 2013

Erratum to: Med Health Care and Philos

DOI 10.1007/s11019-013-9514-0

On the last page of the article, the self-reference referred to:

Zeiler, K., L. Guntram, and A. Lennerling. 2010. Moral tales of parental live kidney donation. A parenthood moral imperative and its relevance for parental living kidney donors' decision-making. Medicine, Health Care and Philosophy 13(3): 225-236.

The article is part of my work as Pro Futura Scientia Fellow.

The online version of the original article can be found under doi:10.1007/s11019-013-9514-0.

K. Zeiler $(\square)$

Department of Medical and Health Sciences, Linköping

University, Linköping, Sweden

e-mail: Kristin.Zeiler@liu.se

K. Zeiler

Swedish Collegium for Advanced Study, Uppsala University,

Uppsala, Sweden 